\title{
Comparison of balance in seated and non-seated employees of Shiraz University of Medical Sciences
}

\author{
DOI: https://doi.org/10.5114/pq.2019.83059
}

\author{
Fatemeh Jabarifard', Mahbobeh Samani', Farahnaz Ghafarinejad', Soraya Pirouzi', Javad Rasouli² \\ ${ }^{1}$ Physical Therapy Department, School of Rehabilitation Sciences, Shiraz University of Medical Sciences, Shiraz, Iran \\ 2 Department of Epidemiology and Biostatistics, School of Medicine, Urmia University of Medical Science, Urmia, Iran
}

Abstract

Introduction. Developments in modern technology in occupational settings have resulted in prolonged sitting at the workplace. Prolonged sedentarism may cause musculoskeletal complications and impaired balance. The present study aimed to evaluate balance in employees working in a seated position for more than half of their working day compared with employees working in a non-seated position.

Methods. Overall, 100 employees entered the study and were divided into the seated $(n=50)$ and non-seated $(n=50)$ groups. The star excursion balance test was used to measure dynamic balance in the lower extremities. Independent t-tests were applied for between-group comparisons.

Results. The star excursion balance test scores were significantly lower in the seated position group compared with the non-seated position group.

Conclusions. We conclude that dynamic stability is lower in employees working in a seated position compared with their non-seated counterparts.

Key words: seated position, core muscles, balance, star excursion balance test, non-seated position

\section{Introduction}

Currently, developments in modern technology and the use of computers and automated systems in occupational settings have resulted in workers remaining in a seated position for prolonged periods, with reduced physical activity and increased workplace sedentarism [1, 2]. The musculoskeletal system requires functional movements such as weightbearing activity and muscle contractions to maintain body position within physiological limits [3]. Hence, prolonged sedentary postures, such as sitting, significantly influence the mechanical properties of biological tissues, leading to musculoskeletal complications and impaired body function $[4,5]$. In addition, it is believed that in the sitting position, core muscle activity is reduced [6]. One of the main roles of core muscles is to maintain balance, which is a major component of the neuromuscular system [7]. Thus, impaired core muscle function as a result of prolonged sitting may lead to dysfunctions in general stability and subsequently musculoskeletal disorders [8].

Many occupations require employees to work in a seated position, and most available studies have investigated musculoskeletal dysfunction during sitting [9-11]. Few, if any, studies have focused on the effect of sitting on balance. The present study was conducted to evaluate balance in employees working in a seated position for more than half of their working day compared with employees working in a nonseated position.

\section{Subjects and methods}

Assuming $80 \%$ power, $\beta=0.2$, and $\alpha=0.05$, a total of 100 employees entered this descriptive study via convenience sampling. The participants were divided into 2 groups: seated position $(n=50)$ and non-seated position $(n=50)$. The seated group spent more than half of their working day seated, while the non-seated group worked in a sitting position for less than half of their working day. The subjects in both groups were matched for age, height, weight, sex, and body mass index. The demographic characteristics of both groups are presented in Table 1. The star excursion balance test (SEBT) was used to measure the dynamic balance in the lower extremities.

The inclusion criteria were as follows:

- employees aged 25-50 years;

- work experience of more than 5 years;

- no signs of back pain or a maximum visual analogue scale score of 2 out of 10 ;

- no history of rehabilitation exercise including back stabilization or balance exercises during the previous year;

- absence of systemic disorders such as diabetes and rheumatoid arthritis;

- absence of neurologic or neuromuscular diseases;

- no prior history of bone fractures or lower limb or spinal cord surgery;

- absence of uncorrected vision impairments;

- no prior history of head trauma;

- absence of self-reported middle ear or balance disorders;

- use of a computer at work for at least 1 hour a day;

- in the seated group: working in a seated position for more than half of the working day;

Correspondence address: Farahnaz Ghafarinejad, Physical Therapy Department, School of Rehabilitation Sciences, Rehabilitation Science Research Center, Shiraz University of Medical Sciences, Abiverdi 1, Shiraz, Iran, e-mail: ghafarif@sums.ac.ir 
Table 1. Demographic characteristics of the study population

\begin{tabular}{|l|c|c|c|}
\hline \multirow{2}{*}{ Characteristics } & \multicolumn{2}{|c|}{ Group } \\
\cline { 2 - 4 } & $\begin{array}{c}\text { Seated }(n=50) \\
\text { mean } \pm S D\end{array}$ & $\begin{array}{c}\text { Non-seated }(n=50) \\
\text { mean } \pm S D\end{array}$ & $\begin{array}{c}\text { Total }(n=100) \\
\text { mean } \pm S D\end{array}$ \\
\hline Gender (male/female) & $21 / 29$ & $21 / 29$ & $42 / 58$ \\
\hline Age (years) & $37.94 \pm 6.08$ & $37.54 \pm 5.86$ & $37.74 \pm 5.94$ \\
\hline Weight $(\mathrm{kg})$ & $68.00 \pm 13.21$ & $68.34 \pm 12.59$ & $68.17 \pm 12.84$ \\
\hline Height $(\mathrm{cm})$ & $164.74 \pm 8.62$ & $166.10 \pm 7.76$ & $165.42 \pm 8.19$ \\
\hline Body mass index (kg/m²) & $24.93 \pm 3.62$ & $166.10 \pm 7.76$ & $24.78 \pm 3.41$ \\
\hline Work experience (years) & $13.98 \pm 6.24$ & $13.36 \pm 6.14$ & $13.67 \pm 6.161$ \\
\hline
\end{tabular}

- in the non-seated group: working in a seated position for less than half of the working day.

The exclusion criteria were:

- pregnancy;

- refusal to continue participating or to complete the tests.

\section{Procedure}

The inclusion and exclusion criteria were verified by observation and data collection forms. Then the participants were informed about the study aim and procedures. Balance was established with the SEBT, which has been shown to be a reliable measure and is used as an index of dynamic postural control, with strong within-tester and between-tester reliability [12-14].

During the test, the subject stood barefoot on one leg and reached with the other leg in 8 different directions (anterior, anterolateral, lateral, posterolateral, posterior, posteromedial, medial, and anteromedial) while pushing the indicator box as far away as possible.

All participants performed right leg trials first, followed by left leg trials. The rest intervals between same-leg trials and between trials with different legs were 15 seconds and 1 minute, respectively. The examiner recorded the reach distance values for each direction in centimetres. Each participant performed enough trials to provide at least 3 valid results, which were used to obtain composite scores. The trials were nor- malized to limb length (\% limb length in $\mathrm{cm}$ ) by measuring the distance from the anterior superior iliac spine to the medial malleolus.

\section{Statistical analysis}

Statistical analyses were done with SPSS software version 21 (SPSS, Chicago, USA). The Kolmogorov-Smirnov test confirmed the normal distribution of the data. Independent $t$-tests were used for between-group comparison.

\section{Ethical approval}

The research related to human use has been complied with all the relevant national regulations and institutional policies, has followed the tenets of the Declaration of Helsinki, and has been approved by the Research Ethics Committee of Shiraz University of Medical Sciences.

\section{Informed consent}

Informed consent has been obtained from all individuals included in this study.

\section{Results}

The results of independent $t$-tests showed that SEBT scores were significantly lower in the seated group compared with the non-seated group. The individuals in the seated

Table 2. Results of independent $t$-tests for star excursion balance test scores

\begin{tabular}{|c|c|c|c|c|c|c|}
\hline \multirow{3}{*}{ Test direction } & \multicolumn{6}{|c|}{ Group } \\
\hline & \multicolumn{2}{|c|}{ Seated $(n=50)$} & \multicolumn{2}{|c|}{ Non-seated $(n=50)$} & \multicolumn{2}{|c|}{ Significance (2-tailed test) } \\
\hline & $\begin{array}{c}\text { Right } \\
(\text { mean } \pm S D)\end{array}$ & $\begin{array}{c}\text { Left } \\
(\text { mean } \pm S D)\end{array}$ & $\begin{array}{c}\text { Right } \\
(\text { mean } \pm S D)\end{array}$ & $\begin{array}{c}\text { Left } \\
(\text { mean } \pm S D)\end{array}$ & $\begin{array}{l}\text { Right leg as the } \\
\text { stance limb }\end{array}$ & $\begin{array}{l}\text { Left leg as the } \\
\text { stance limb }\end{array}$ \\
\hline Anterior & $107.69 \pm 14.18$ & $108.03 \pm 13.41$ & $126.64 \pm 11.21$ & $130.46 \pm 11.88$ & $<0.01$ & $<0.01$ \\
\hline Anterolateral & $100.06 \pm 10.72$ & $101.05 \pm 13.67$ & $120.96 \pm 20.55$ & $119.82 \pm 18.70$ & $<0.01$ & $<0.01$ \\
\hline Lateral & $73.86 \pm 14.16$ & $72.34 \pm 13.88$ & $96.43 \pm 18.37$ & $98.77 \pm 17.66$ & $<0.01$ & $<0.01$ \\
\hline Posterolateral & $78.39 \pm 16.30$ & $76.43 \pm 12.51$ & $106.53 \pm 16.60$ & $105.57 \pm 19.40$ & $<0.01$ & $<0.01$ \\
\hline Posterior & $81.49 \pm 13.34$ & $80.62 \pm 14.28$ & $108.19 \pm 15.50$ & $110.64 \pm 23.60$ & $<0.01$ & $<0.01$ \\
\hline Posteromedial & $164.98 \pm 43.47$ & $153.83 \pm 40.29$ & $139.22 \pm 54.40$ & $139.52 \pm 40.88$ & $<0.01$ & $<0.01$ \\
\hline Medial & $103.51 \pm 11.66$ & $103.91 \pm 23.37$ & $127.23 \pm 17.25$ & $127.58 \pm 20.15$ & $<0.01$ & $<0.01$ \\
\hline Anteromedial & $112.04 \pm 12.84$ & $110.68 \pm 15.40$ & $132.53 \pm 15.28$ & $138.72 \pm 18.24$ & $<0.01$ & $<0.01$ \\
\hline Composite Score & $115.25 \pm 11.36$ & $113.36 \pm 11.23$ & $144.72 \pm 14.51$ & $146.38 \pm 16.50$ & $<0.01$ & $<0.01$ \\
\hline
\end{tabular}


group had significantly shorter reach distances than those in the non-seated group for all directions in the SEBT, and for both the left and right leg as the stance limb (Table 2).

\section{Discussion}

The findings of this study show that sitting for prolonged periods at work was associated with reduced balance. To our knowledge, there are no similar studies designed to compare dynamic balance in employees who work while seated vs. those who work mostly in a non-seated position, which precludes comparisons of our results with previous research. However, findings consistent with our results were reported by Søndergaard et al. [15]. The authors investigated postural control during sitting and observed increased standard deviations for the centre of pressure and decreased complexity of sitting posture after prolonged sitting. These can be considered possible factors that contribute to impaired balance in persons who remain seated for long periods while at work.

The supporting surface is increased while sitting, and core muscle activity is reduced. Instead, passive lumbopelvic structures maintain posture against gravity [16]. Core muscles such as the lumbopelvic and hip muscles are located in the centre of the movement chain, and produce, transport, and control energy throughout the full functional kinetic chain $[17,18]$. Thus, a prolonged decrease in core muscle activity may cause maladaptation in the motor control system and lead to dysfunctions in overall stability along with musculoskeletal disorders [19]. Therefore, the reduced balance in our seated position group may be related to the lowered core muscle activity due to prolonged sitting.

Another possible reason for the impaired core muscle function and lower balance in our seated position group compared with the non-seated position group may be the development of creep phenomena during prolonged sitting. These phenomena occur after a continuous load due to collagen matrix disruption and interstitial fluid compression. The induced load can change the mechanical properties of viscoelastic materials, resulting in muscle fatigue [20, 21]. Moreover, there is evidence that creep and prolonged tension may change mechanoreceptor thresholds in viscoelastic paraspinal tissues, which may in turn lead to delayed muscle reflexes [22]. Therefore, the impaired balance in our seated position group may have also been a result of delayed core muscle reflexes.

A further factor to consider is that prolonged sitting places a greater load on lumbar viscoelastic structures, especially on the intervertebral discs. This can be another reason for impaired core muscle function and impaired balance in sitting positions compared with standing positions. It has been reported that pressures within the intervertebral disc during sitting are approximately twice as high as in the standing position [23].

Solomonow et al. [21] proposed that the creep in viscoelastic tissues recovered during a subsequent 7-hour rest. However, spasms and acute soft tissue inflammation were observed early in the recovery period, and 48 hours were required for full recovery $[20,21]$. It is possible that full recovery did not occur in employees who worked while seated for prolonged periods, leading to spasms and accumulated inflammation, which caused musculoskeletal disorders and balance deficiency.

The SEBT is considered a measure of neuromuscular control; thus, individuals with lower scores are assumed to have lower levels of neuromuscular integration, which in turn may constitute a risk factor for injuries [13]. Accordingly, lower performance on the SEBT in our seated position group suggests that prolonged occupational sitting is associated not only with decreased core muscle function, but also with some degree of neuromuscular control impairment. Although most participants in the present study were right-footed, the SEBT results were the same for the left and right limbs. This is consistent with findings reported by Demura and Yamada [24], but contrasts with a previous study in which neuromuscular function was found to be lower in the non-dominant leg than in the dominant limb [25].

\section{Limitations and strengths}

Our study is the first to evaluate dynamic balance with the SEBT in employees working in a seated compared with a non-seated position. However, an unequal proportion of male and female participants in our 2 groups and the use of a relatively young and healthy sample are the main limitations of our study. In addition, we did not evaluate the magnitude of physical activity or physical fitness in either group. Because these factors may affect the SEBT results, future studies based on similar methods should assess physical activity and physical fitness.

\section{Conclusions}

The findings of the present study show that dynamic stability was lower in employees who worked for prolonged periods in a seated position than in their counterparts working mostly in a non-seated position.

\section{Acknowledgements}

This work was financially supported by Shiraz University of Medical Sciences. We thank K. Shashok (AuthorAID in the Eastern Mediterranean) for improving the use of English in the manuscript.

\section{Disclosure statement}

No author has any financial interest or received any financial benefit from this research.

\section{Conflict of interest}

The authors state no conflict of interest.

\section{References}

1. Parry S, Straker L. The contribution of office work to sedentary behaviour associated risk. BMC Public Health. 2013;13(1):296; doi: 10.1186/1471-2458-13-296.

2. Choi $B$, Schnall PL, Yang H, Dobson M, Landsbergis $P$, Israel L, et al. Sedentary work, low physical job demand, and obesity in US workers. Am J Ind Med. 2010;53(11): 1088-1101; doi: 10.1002/ajim.20886.

3. Ayanniyi O, Ukpai BO, Adeniyi A. Differences in prevalence of self-reported musculoskeletal symptoms among computer and non-computer users in a Nigerian population: a cross-sectional study. BMC Musculoskelet Disord. 2010;11(1):177; doi: doi: 10.1186/1471-247411-177.

4. Fasih Ramandi F, Nadri F, Moussavi Najarkola SA, Nadri H, Karamhkani M. Evaluation of musculoskeletal disorders risk factors by REBA and QEC methods in an aluminum industry. Health Develop J. 2016;5(2):122-133.

5. Janwantanakul $P$, Pensri $P$, Jiamjarasrangsi W, Sinsongsook T. Associations between prevalence of self-reported musculoskeletal symptoms of the spine and biopsy- 
chosocial factors among office workers. J Occup Health. 2009;51(2):114-122; doi: 10.1539/joh.L8105.

6. Lafond D, Champagne A, Descarreaux M, Dubois JD, Prado JM, Duarte M. Postural control during prolonged standing in persons with chronic low back pain. Gait Posture. 2009;29(3):421-427; doi: 10.1016/j.gaitpost.2008. 10.064.

7. Maribo T, Schiøttz-Christensen B, Jensen LD, Andersen NT, Stengaard-Pedersen K. Postural balance in low back pain patients: criterion-related validity of centre of pressure assessed on a portable force platform. Eur Spine J. 2012;21(3):425-431; doi: 10.1007/s00586-011-1981-5.

8. Yoo W-G, An D-H. The relationship between the active cervical range of motion and changes in head and neck posture after continuous VDT work. Ind Health. 2009; 47(2):183-188; doi: 10.2486/indhealth.47.183.

9. Madeleine $P$, Vangsgaard S, Andersen JH, Ge H-Y, Arendt-Nielsen L. Computer work and self-reported variables on anthropometrics, computer usage, work ability, productivity, pain, and physical activity. BMC Musculoskelet Disord. 2013;14(1):226; doi: 10.1186/1471-247414-226.

10. Naqvi M, Zehra M, Nizami GN. Association of prolong sitting with common musculoskeletal disorders among private and public sector bankers. Pak J Rehabil. 2013; 2(2):48-56.

11. Sharan D, Parijat $P$, Sasidharan AP, Ranganathan $R$, Mohandoss M, Jose J. Workstyle risk factors for work related musculoskeletal symptoms among computer professionals in India. J Occup Rehabil. 2011;21(4): 520-525; doi: 10.1007/s10926-011-9294-4.

12. Hertel J, John Miller S, Denegar CR. Intratester and intertester reliability during the star excursion balance tests. J Sport Rehabil. 2000;9(2):104-116; doi: 10.1123/ jsr.9.2.104.

13. Filipa A, Byrnes R, Paterno MV, Myer GD, Hewett TE. Neuromuscular training improves performance on the star excursion balance test in young female athletes. J Orthop Sports Phys Ther. 2010;40(9):551-558; doi: 10.2519/ jospt.2010.3325.

14. Kinzey SJ, Armstrong CW. The reliability of the starexcursion test in assessing dynamic balance. J Orthop Sports Phys Ther. 1998;27(5):356-360; doi: 10.2519/ jospt.1998.27.5.356.

15. Søndergaard KH, Olesen CG, Søndergaard EK, de Zee M, Madeleine P. The variability and complexity of sitting postural control are associated with discomfort. J Biomech. 2010;43(10):1997-2001; doi: 10.1016/j. jbiomech.2010.03.009.

16. O’Sullivan PB, Mitchell T, Bulich P, Waller R, Holte J. The relationship between posture and back muscle endurance in industrial workers with flexion-related low back pain. Man Ther. 2006;11(4):264-271; doi: 10.1016/j.math. 2005.04.004.

17. Prakash JS, Singh V, Prakash J, Bhatty S, Deane A. Computer usage and musculoskeletal disorders [MSD's]. WebmedCentral Orthopaedics. 2014;5(1):WMC004506.

18. Kang J-H, Park R-Y, Lee S-J, Kim J-Y, Yoon S-R, Jung K-I. The effect of the forward head posture on postural balance in long time computer based worker. Ann Rehabil Med. 2012;36(1):98-104; doi: 10.5535/arm.2012.36.1.98.

19. O'Sullivan PB. Lumbar segmental 'instability': clinical presentation and specific stabilizing exercise management. ManTher.2000;5(1):2-12; doi:10.1054/math.1999.0213.

20. O'Sullivan PB, Grahamslaw KM, Kendell M, Lapenskie SC, and sitting postures on trunk muscle activity in a painfree population. Spine. 2002;27(11):1238-1244; doi: 10.1097/00007632-200206010-00019.

21. Solomonow M, Baratta RV, Banks A, Freudenberger C, Zhou $\mathrm{BH}$. Flexion-relaxation response to static lumbar flexion in males and females. Clin Biomech. 2003;18(4): 273-279; doi: 10.1016/S0268-0033(03)00024-X.

22. Little JS, Khalsa PS. Human lumbar spine creep during cyclic and static flexion: creep rate, biomechanics, and facet joint capsule strain. Ann Biomed Eng. 2005;33(3): 391-401; doi: 10.1007/s10439-005-1742-x.

23. Wilke HJ, Neef $P$, Caimi M, Hoogland T, Claes LE. New in vivo measurements of pressures in the intervertebral disc in daily life. Spine. 1999;24(8):755-762; doi: 10.1097/ 00007632-199904150-00005.

24. Demura S, Yamada T. Proposal for a practical star excursion balance test using three trials with four directions. Sport Sci Health. 2010;6(1):1-8; doi: 10.1007/s11332010-0089-3.

25. Olmsted LC, Carcia CR, Hertel J, Shultz SJ. Efficacy of the star excursion balance tests in detecting reach deficits in subjects with chronic ankle instability. J Athl Train. 2002;37(4):501-506. 